\title{
An Ultrastructural Study of GABA-Immunoreactive Neurons and Terminals in the Septum of the Rat
}

\author{
Brigitte Onténiente, ${ }^{1}$ Michel Geffard, ${ }^{2}$ Ghislaine Campistron, ${ }^{2}$ and André Calas ${ }^{2}$ \\ 'Laboratoire de Physiologie des Interactions Cellulaires, UA CNRS 339, F-33405 Talence Cedex, and ${ }^{2} \mid B C N$ CNRS, \\ Laboratoire de Neuroimmunologie, F-33077 Bordeaux, France
}

\begin{abstract}
The fine structure and types of contact made by GABAergic elements in the septal nuclei were studied at the electronmicroscopic level by means of peroxidase immunocytochemistry, using anti-GABA antibodies. Observations were made on normal and colchicine-injected rats.

GABA-immunoreactivity was distributed within somata, dendrites, axonal varicosities and terminals, and myelinated axons. The peroxidase reaction product was diffuse in the cytoplasm; cytoplasmic organelles were generally devoid of immunoreactivity, while showing a strong reaction on the outer surface of their membrane. GABA-immunoreactive (GABA-I) neurons were small (10 $\mu \mathrm{m}$ on average) to medium $(20 \mu \mathrm{m})$ in size, with round or multipolar cell bodies. Additionally, labeled large $(30 \mu \mathrm{m})$ cells were observed within the myelinated fibers of the medial septal nucleus after intraseptal administration of colchicine. No difference in the ultrastructural features and distribution of the immunoreactivity of the 2 kinds of cell was noticed, except for a higher number of synaptic contacts on large neurons of the medial septum.
\end{abstract}

GABA-I cells of the medial and lateral nuclei received synapses on their soma and dendrites, made by both immunonegative and GABA-I terminals. Nonimmunoreactive boutons contacting GABA-I cell bodies were of 2 types: those containing small, clear synaptic vesicles and those that additionally contained large dense vesicles. Synaptic vesicles of GABA-I boutons were rarely labeled internally, but showed varying electron densities. Synapses made by GABA-I boutons on GABA-I or unlabeled somata and dendrites were always of symmetrical type. Synapses made by non-GABA-I boutons on GABA-I cells were either symmetrical or asymmetrical.

The inhibitory amino acid $\gamma$-aminobutyric acid (GABA) represents a substantial proportion of the transmitters present in the septal region (Walaas and Fonnum, 1979). Immunohistochemistry using anti-GABA antibodies has provided descriptions of the regional distribution of GABA-immunoreactive elements in the rat septum (Ottersen and Storm-Mathisen, 1984; Onténiente et al., 1986) that correlate previous studies per-

\footnotetext{
Received Mar. 10, 1986; revised June 10, 1986; accepted June 20, 1986.

The authors wish to thank C. Baradet for her photographic assistance. This work was supported by grants from INSERM (83/6005) and the FRM (to A.C.).

Correspondence should be addressed to B. Onténiente, Lab. Physiologie des Interactions Cellulaires, Univ. Bordeaux I, Av. des Facultés, F-33405 Talence Cedex, France

Copyright (c) 1987 Society for Neuroscience $0270-6474 / 87 / 010048-07 \$ 02.00 / 0$
}

formed with antibodies directed against the GABA-synthesizing enzyme L-glutamate decarboxylase (GAD) (Costa et al., 1983; Köhler and Chan-Palay, 1983; Panula et al., 1984). In the lateral septal nucleus, randomly distributed cell bodies were described as part of an important network of GABA-containing axonal varicosities, while the medial part contained mostly GABAergic cells among the myelinated fiber tracts. Physiological data (De France, 1976), supported by anatomical differences (Panula et al., 1984; Onténiente et al., 1986), suggested the existence of 2 functionally distinct GABAergic systems in the lateral and medial septal nuclei.

The functional significance of GABA within the septum is probably related to its general inhibitory action. Electrophysiological studies showed the involvement of GABA in the control of electrical activity in the septohippocampal axis (McLennan and Miller, 1974). Different roles in endocrine regulation via the septohypothalamic route have also been evidenced (De Feudis, 1984). However, ultrastructural studies giving morphological support to such interactions of GABAergic elements with other components of the septal area are lacking.

This study aimed at determining, by means of peroxidase immunocytochemistry applied to anti-GABA antibodies, the ultrastructural features and types of contact displayed by GABAcontaining structures in the lateral and medial septal nuclei.

\section{Materials and Methods}

Twenty male adult Wistar rats weighing $200 \mathrm{gm}$ were used. Twentyfour hours before they were killed, 10 animals received, under pentobarbital anaesthesia ( $35 \mathrm{mg} / \mathrm{kg}$ ), an injection of $10 \mu \mathrm{g}$ colchicine (Sigma) in $1 \mu \mathrm{l}$ saline solution into the frontal part of the medial septum at the "Bregma $1 \mathrm{~mm}$ " level of the atlas of Paxinos and Watson (1982). After fresh anaesthesia, normal and colchicine-injected rats were perfused via the ascending aorta by an ice-cold mixture of $5 \%$ glutaraldehyde in 0.1 M cacodylate buffer, $\mathrm{pH} 7.2$. Brains were removed, the septal region dissected out and immersed in the same fixative for an additional 45 min. Vibratome sections, $50 \mu \mathrm{m}$ thick, were cut and washed for $1 \mathrm{hr}$ in $0.1 \mathrm{M}$ Tris buffer, $\mathrm{pH} 7.2$

GABA antibodies (Seguela et al., 1984) were used at a dilution of 1: 4000 in the same buffer for an overnight incubation at $4^{\circ} \mathrm{C}$. After 30 min of washing, the sections were incubated in peroxidase-labeled Fab fragments of anti-rabbit IgG (1:1000; Biosys) for $1 \mathrm{hr}$ at room temperature and washed for $30 \mathrm{~min}$ in Tris buffer. The peroxidase activity was revealed by reaction with $3-3$ ', diaminobenzidine $(0.025 \%$; Sigma) in $0.05 \mathrm{M}$ Tris buffer containing $0.01 \% \mathrm{H}_{2} \mathrm{O}_{2}$.

Immunocytochemical controls were performed on sections of both colchicine-treated and normal animals by incubation in normal rabbit serum or in primary antiserum previously adsorbed by its immunogen.

After observation of the immunocytochemical reaction under the light microscope, the sections were postfixed in $1 \%$ osmium tetroxide for 1 $\mathrm{hr}$, dehydrated, and flat-embedded in Epon 812. After polymerization, they were again observed under the light microscope, pieces of interest were cut off and attached to Epon supports for ultrathin sectioning on 

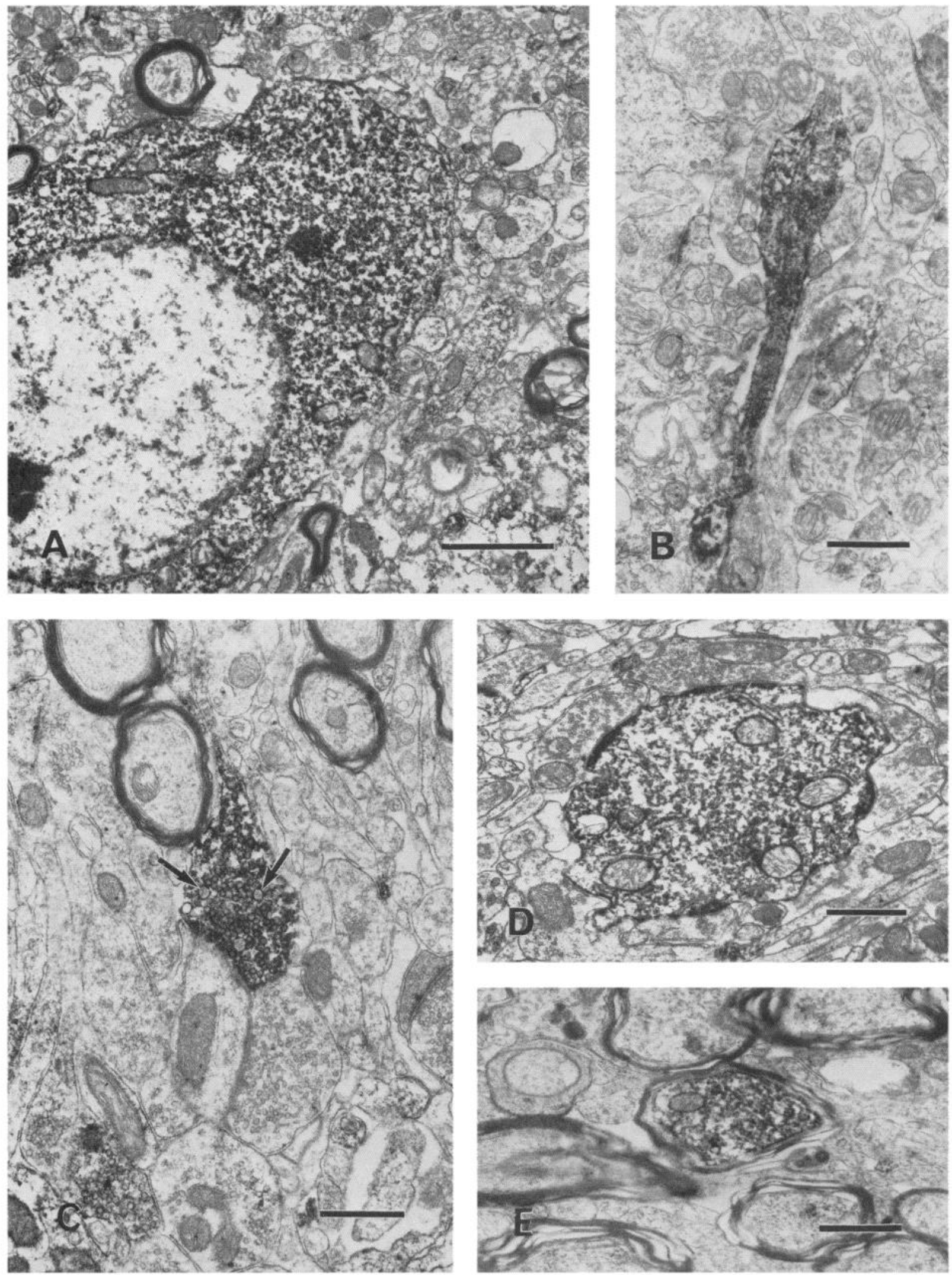

Figure 1. Electron micrographs of the rat septum after peroxidase immunocytochemistry with anti-GABA antibodies. $A$, GABA-labeled cell body. The immunoreaction product is diffusely spread over the cytoplasm, sparing the nucleus and the cytoplasmic organelles. Bar, $1.5 \mu$ m. $B$, GABAlabeled unmyelinated axon cut longitudinally shows a varicosity containing clear synaptic vesicles. Bar, $0.74 \mu \mathrm{m}$. $C$, Within GABA-labeled terminals, the peroxidase reaction product is linked to the external side of the membranes of synaptic and large, unlabeled vesicles (arrows). Bar, $0.56 \mu$ m. $D$, Labeled dendrites show the same distribution pattern of immunoreaction as cell bodies. This dendrite receives asymmetrical synapses showing a dense accumulation of immunoreaction product at postsynaptic sites. Bar, $0.71 \mu \mathrm{m}$. E, GABA-immunoreactive, myelinated axons are frequent in the medial septal nucleus. Bar, $0.75 \mu \mathrm{m}$. 

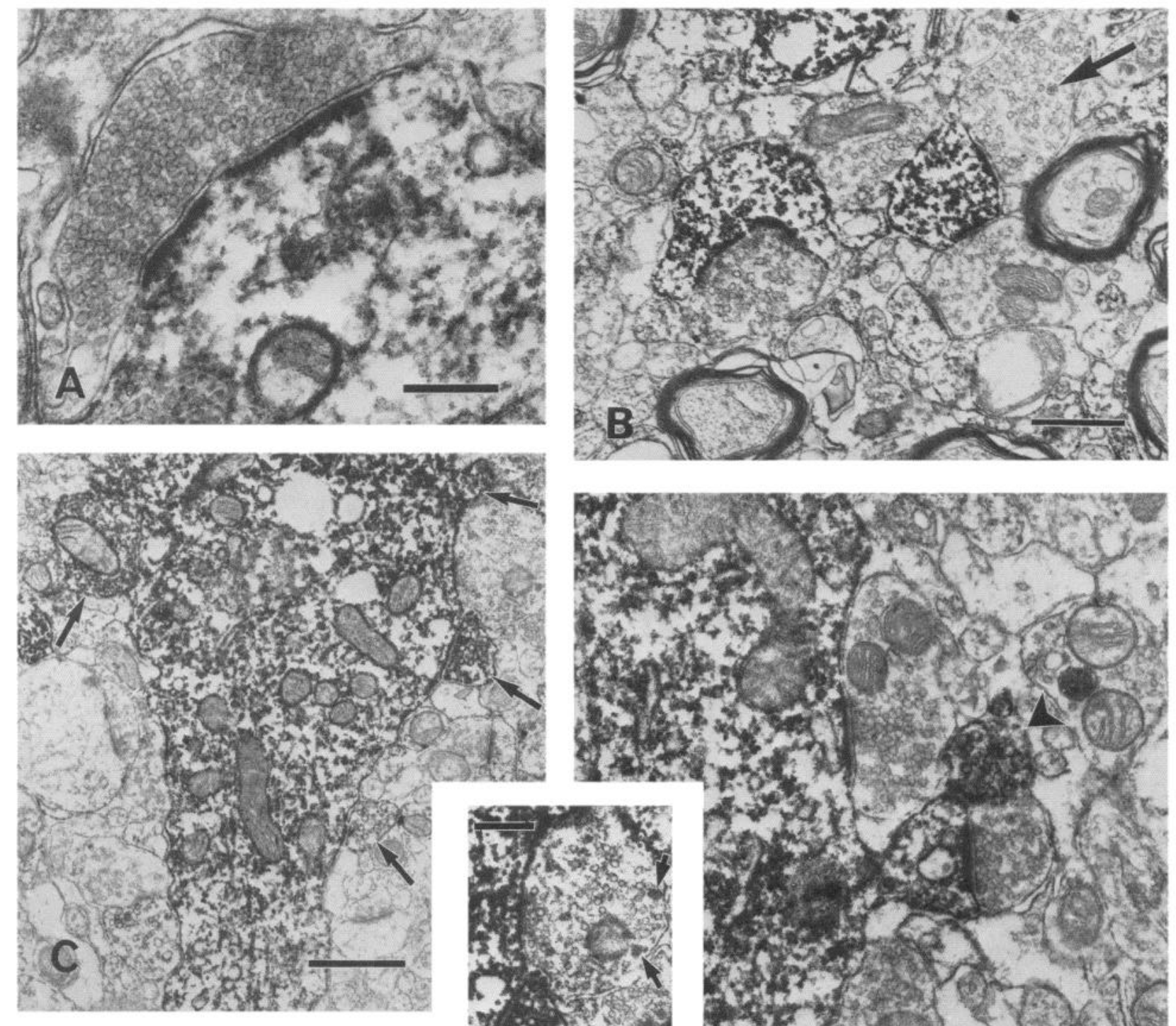

\section{.}
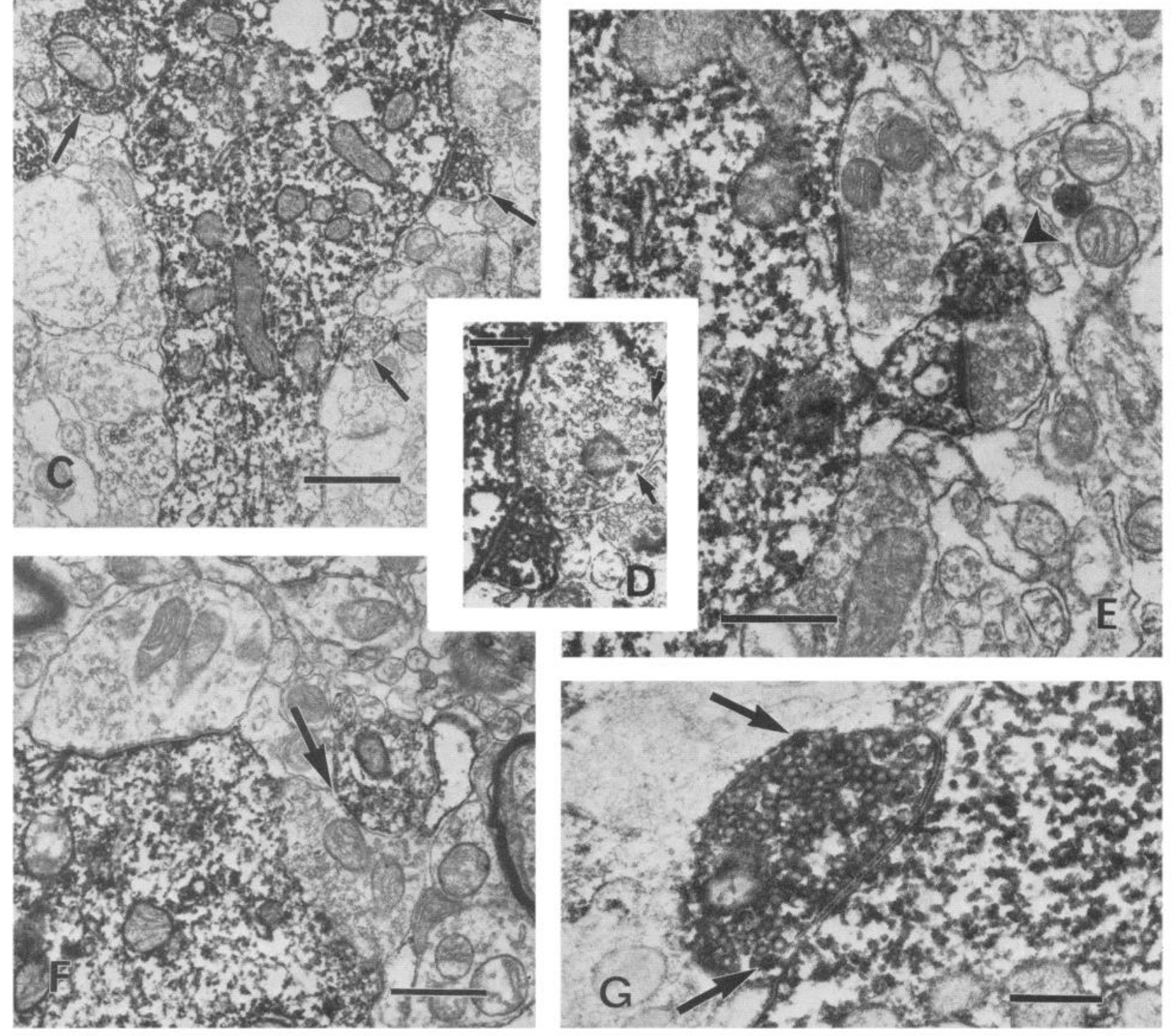

Figure 2. Electron micrographs of GABA-immunoreactive (GABA-I) elements in the lateral septal nucleus of the rat. A, Asymmetrical synapses between a nonlabeled terminal and a GABA-I dendrite. A dense accumulation of immunoreactive material is seen at the postsynaptic site. Bar, $0.7 \mu \mathrm{m}$. B, GABA-I dendrites postsynaptic to unlabeled terminals. A large, dense-cored vesicle (arrow) is seen within one of them. Bar, $0.56 \mu \mathrm{m}$. $C$, Initiation point of a dendrite in a GABA-I neuron showing symmetrical synaptic contacts with GABA-I (arrows) and unlabeled boutons. Bar, $0.71 \mu \mathrm{m}$. $D$, Higher magnification of $C$. Large dense vesicles (arrows) are seen within the unlabeled profile. Bar, $0.38 \mu \mathrm{m}$. $E$, Two adjacent boutons in synaptic contact with a somatic spine made by a GABA-I neuron, one of which is labeled (arrowhead). Bar, $0.6 \mu \mathrm{m}$. $F$, A contact (arrow) between 
a Reichert OmU2 ultramicrotome. Ultrathin sections were contrasted with uranyl acetate and lead citrate and observed on a Philips 300 electron microscope.

\section{Results}

\section{General characteristics of GABA-immunolabeling}

In the Vibratome sections observed under a light microscope, GABA-immunoreactive (GABA-I) elements included nerve cell bodies, with their proximal dendrites and punctate profiles overlying the whole septum. Punctate profiles were frequently seen on GABA-I neurons. Control sections were completely devoid of immunoreaction.

Topical injections of colchicine revealed an additional group of GABA-I neurons of large size $(30 \mu \mathrm{m})$ in the medial septum.

Ultrathin sections of the lateral septum showed GABA-immunoreaction within medium-sized (10-20 $\mu \mathrm{m})$ somata (Fig. $1 A$ ) and dendrites (Fig. $1 D$ ), synaptic boutons (Fig. 1C), and small unmyelinated axons (Fig. $1 B$ ). In addition, large GABA-I cells (Fig. 3E) and myelinated axons (Fig. $1 E$ ) were found in the medial septum. The general distribution pattern of the immunoreaction was similar within the 2 populations of cells (Figs. $1 A$ and $3 A$ ): diffuse in the cytoplasm, occasionally present in the nucleus, with no precise relationship with cytoplasmic organelles, and associated with the external side of their membrane.

Punctate profiles observed in the light microscope were shown by electron microscopy to be axonal boutons, terminals, or cross sections of small dendrites. The density of GABA-I dendrites was much higher than that of GABA-I synaptic boutons, which were labeled only within a depth of $5 \mu \mathrm{m}$ in the sections. As a counterpart, synaptic boutons displayed a more intense labeling than adjacent dendrites and cell bodies. GABA-I axonal varicosities contained round synaptic vesicles with varying internal electron densities which were very rarely immunolabeled (Fig. $2 G$ ). The peroxidase product was found in the cytoplasm between the vesicles, linked to the outer surface of vesicular and mitochondrial membranes, and within aggregates at synaptic sites. Large, granulated vesicles of $60-80 \mathrm{~nm}$ were occasionally observed within GABA-I boutons, with no internal immunoreactivity (Fig. $1 C$ ).

\section{Synaptic organization}

The large GABA-I neurons of the medial septum received a greater number of synapses than did the smaller ones. Four types of presynaptic elements were observed: (1) non-GABA-I terminals with small synaptic vesicles (Fig. $2, A, B, E, F$; Fig. 3, $B, C, E)$; (2) non-GABA-I terminals with small synaptic vesicles and large granular $(60-80 \mathrm{~nm})$ vesicles, with varying electron densities (Fig. 2, B, D); (3) GABA-I terminals with synaptic vesicles, some of which were occasionally labeled (Fig. 2, $C-G$; Fig. 3, $A, B, D$ ); and (4) GABA-I terminals with large clear vesicles (Fig. 1C). The third type of synapse could be observed on somatic spines (Fig. $2 E$ ).

Synapses on GABA-I cell bodies and dendrites were generally asymmetrical, with a strong postsynaptic thickening, while symmetrical ones were observed more rarely (Fig. 2, C, D; Fig. 3, $B, E)$. Dense accumulations of immunoreaction end product at postsynaptic sites reinforced the asymmetrical aspect of these synapses (Fig. 1D; Fig. 2, $A, B, E$ ).

In rare cases, GABA-I boutons in contact with unlabeled terminals making synapses with GABA-I somata (Fig. $2 F$ ) were observed.The lack of postsynaptic thickening in symmetrical synapses made it difficult to assess whether such axoaxonic contacts were synapses. However, they presented electron-dense material between the 2 membranes concerned and an accumulation of vesicles close to the site of contact.

\section{Discussion}

\section{Distribution of GABA-immunoreactivity}

Previous biochemical (Seguela et al., 1984) and immunocytochemical (Seguela et al., 1985; Gamrani et al., 1986) studies have established the specificity of the GABA antibody for the detection of GABA within the rat CNS. The distribution of immunoreactive elements was similar to that observed with other antibodies directed against GAD (Costa et al., 1983; Köhler and Chan-Palay, 1983; Panula et al., 1984) and GABA (Ottersen and Storm-Mathisen, 1984; Onténiente et al., 1986).

The ultrastructural distribution of the immunoreaction product resembled that described for GABA immunocytochemistry in previous reports (Somogyi et al., 1985; Gamrani et al., 1986). It was diffuse in somata, dendrites, and nerve terminals, showing no precise relationship with the cytoplasmic organelles except for a binding of immunoreaction product to the external side of their membrane. Some GABA was detected within synaptic vesicles.

The lack of abundant vesicular staining by GABA antibodies has been discussed in detail in a previous report (Gamrani et al., 1986). Biochemical investigations tend to demonstrate that GABA is contained in the terminals within an extravesicular pool (Mangan and Whittaker, 1966; De Belleroche and Bradford, 1977; Kuriyama, 1976). However, a displacement and relocalization of the molecule during biochemical, as well as immunocytochemical, procedures cannot be ruled out. It is worth considering that synaptic vesicles are rarely stained by immunocytochemistry for small molecules such as dopamine (Onténiente et al., 1984; Kah et al., 1986), serotonin (Maxwell et al., 1983), or some peptides (see Pickel, 1985), which have been clearly demonstrated to be contained within synaptic vesicles. The nonvesicular staining may not reflect the absence of GABA within synaptic vesicles, but could result from either a relocalization of GABA during histochemical processing and/or a poor penetration of the antibodies through the vesicular membrane. The latter hypothesis is maintained if we consider that a general labeling of synaptic vesicles by anti-GABA antibodies is observed when the tissue is damaged (unpublished observations and Ottersen and Storm-Mathisen, 1984).

The GABA-immunolabeling of large granulated vesicles reported by Somogyi et al. (1985) and Ottersen and Storm-Mathisen (1984) was not observed in our material. GABA coexists with various neuroactive peptides in several regions of the brain (for a review, see Mugnaini and Oertel, 1985). Concerning the septum, data are lacking. Seventeen peptides have been evidenced in this brain region (Palkovits and Brownstein, 1985), among which substance $P$, enkephalins, somatostatin, and cho-

a GABA-I bouton and an unlabeled terminal in contact with a GABA-I dendrite. Bar, $0.63 \mu \mathrm{m}$. $G$, Some GABA-I vesicles (arrows) are observed within the labeled terminals. Bar, $0.44 \mu \mathrm{m}$. 

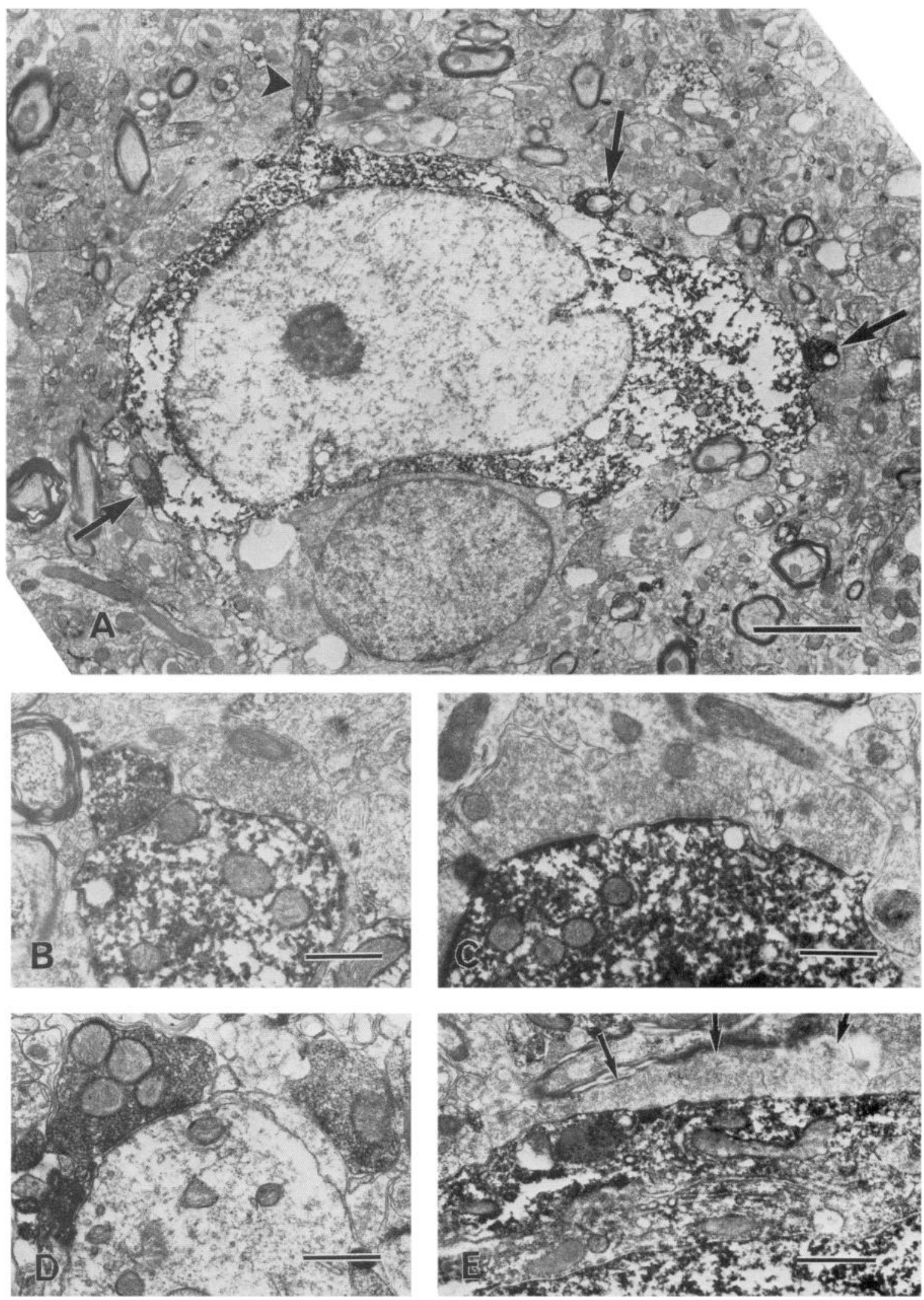

Figure 3. Electron micrographs of GABA-immunoreactive (GABA-I) elements in the medial septum of the rat. $A$, GABA-I neuron of small size with a dendrite elongating from the soma (arrowhead) receives synaptic contacts from GABA-I terminals (arrows). Bar, $1.25 \mu \mathrm{m}$. $B$, Symmetrical synapses between a GABA-I dendrite, a GABA-I bouton, and an unlabeled terminal. Bar, $0.67 \mu \mathrm{m}$. $C$, GABA-I dendrite in asymmetrical synapse with 3 non-labeled terminals. Bar, $0.68 \mu \mathrm{m}$. $D$, GABA-I terminal in symmetrical synaptic contact with an unlabeled dendrite. Bar, $0.86 \mu \mathrm{m}$. $E$ Large GABA-I neurons of the medial septum and diagonal band of Broca receive frequent synapses from unlabeled varicosities (arrows). Bar, 0.66 $\mu \mathrm{m}$. 
lecystokinin are quantitatively the most representative. Doublelabeling studies are necessary in order to form a conclusion as to whether the large non-GABA-I granulated vesicles observed in GABA-I boutons correspond to storage sites of peptidergic cotransmitters.

GABAergic neurons in the brain display a great variability in size and shape. Originally described as consisting of inhibitory interneurons, the GABAergic brain population is now considered to include long-projection neurons (see Ribak et al., 1981; Mugnaini and Oertel, 1985). In the septum, on the basis of the morphological aspect of GAD- (Köhler and Chan-Palay, 1983; Panula et al., 1984) and GABA- (Onténiente et al., 1986) immunoreactive neurons, a dual population of GABAergic cells has been demonstrated. The GABA-I neurons of the lateral division are interneurons (De Feudis, 1984), while the medial nucleus contains, in addition, a group of large GABAergic cells (Köhler and Chan-Palay, 1983; Panula et al., 1984; Onténiente et al., 1986). The large GABA-I neurons of the medial septumdiagonal band of the Broca $(\mathrm{dbB})$ complex were clearly distinguished from others under the electron microscope. No characteristic of their fine structure and synaptic organization could be observed in the smaller cells, except for a higher density of synaptic boutons on cell bodies of large size in the medial septum, which may correlate eventual functional differences.

\section{Synaptic relationships of $G A B A-I$ elements}

Various means of GABAergic inhibition have been electrophysiologically demonstrated in the brain. The morphological evidence for 2 of these was observed in this study. Symmetrical junctions between GABA-I boutons and unlabeled elements were the most frequent, corresponding to postsynaptic inhibition. GABAergic boutons on GABAergic neurons were the second type of synaptic relationship observed, corresponding to disinhibition. GABA-GABA interactions are frequent in the CNS (Ribak et al., 1979; Bolam et al., 1983; Oertel et al., 1984; Mugnaini, 1985) and were observed in the lateral and medial septum, which correlated with electrophysiological data demonstrating an inhibition of inhibitory septal interneurons (De France, 1976). In addition to these 2 kinds of inhibition, axoaxonic contacts were observed between GABA-I and unlabeled terminals forming synapses with GABA-I cell bodies. This finding may reflect presynaptic inhibition. However, since symmetrical synapses lack clcar, postsynaptic thickening, despite the presence of vesicles at the zone of contact, it could not be assessed that such contacts were synapses.

The lateral septal nuclei receive afferents from the hippocampus (Swanson and Cowan, 1979), which contains numerous GABA-I cells (Ribak et al., 1978). However, no evidence for a GABAergic projection from the hippocampus to the septum exists. GABA-I boutons observed on GABA-I neurons probably originate in the septum itself or in other subcortical structures.

The medial septal nucleus receives afferents from the neurons of the lateral nucleus, some of which are GABAergic and may participate in the inhibition of the 2 morphologically distinct GABAergic cell populations of this region. The large GABA-I neurons participate in the septohippocampal pathway (Köhler et al., 1984). It has been electrophysiologically demonstrated that the septohippocampal neurons receive inhibitory inputs (McLennan and Miller, 1974; Dutar ct al., 1985), which arc most probably mediated by GABA. The synaptic interactions observed between GABA-I cell bodies and GABA-I terminals in the medial septum-dbB complex well correlate this fact and may demonstrate a disinhibition of GABAergic septohippocampal neurons by GABAergic septal interneurons. Further studies would be necessary to determine whether this inhibition is mediated by local or extrinsic neurons, or is due to recurrent collaterals, as was suggested by De France (1976).

\section{Relationships with other neuronal systems}

The lateral septum contains most of the known neurotransmitters and neuroactive substances. A great number of peptides and amino acids (Ottersen and Storm-Mathisen, 1984) have been evidenced within cell bodies, while afferents include peptidergic fibers arising from the hypothalamic area (DeVries and Buijs, 1983; Poulain et al., 1984), dopaminergic fibers from the ventrotegmental area (Lindvall and Stenevi, 1978; Moore, 1978; Simon et al., 1979), serotoninergic fibers from the raphe nuclei (Azmitia and Segal, 1978; Köhler et al., 1982) and noradrenergic fibers from the locus coeruleus (Swanson and Hartman, 1975; Moore, 1978). Some of these projections (dopamine: Onténiente et al., 1984; enkephaline and substance P: Gall and Moore, 1984; serotonin: Köhler et al., 1982; Gall and Moore, 1984) display a characteristic pericellular distribution that could correspond to the high density of unlabeled boutons observed on GABA-I cells.

Within the medial septum-dbB complex, the implication of GABA in the dopaminergic regulation of cholinergic septohippocampal cells is well known (Cheney et al., 1978). Interactions have also been shown between GABAergic fibers and gonadotrophin-releasing hormone (Jennes et al., 1983). Double-labeling studies are now necessary to gain more information about the complex relationships between $\mathrm{GABA}$ and the various neurotransmitters contained within this brain region.

\section{References}

Azmitia, E. C., Jr., and M. Segal (1978) An autoradiographic analysis of the different ascending projections of the dorsal and medial raphe nuclei in the rat. J. Comp. Neurol. 179: 641-668.

Bolam, J. P., D. J. Clarke, A. D. Smith, and P. Somogyi (1983) A type of aspiny neurons in the rat neostriatum accumulates $\left[{ }^{3} \mathrm{H}\right] \gamma$ aminobutyric acid: Combination of Golgi-staining, autoradiography, and electron microscopy. J. Comp. Neurol. 213: 121-134.

Cheney, D. L., S. E. Robinson, D. Malthe-Sørenssen, P. L. Wood, J. W. Comminssiong, and E. Costa (1978) Regulation of the cholinergic septal-hippocampal pathway: Role of dopaminergic septal afferents. In Neuropsychopharmacology, Vol. 5, C. Dumont, ed., pp. 241-250, Pergamon, New York.

Costa, E., P. Panula, H. K. Thompson, and D. L. Cheney (1983) Minireview. The transynaptic regulation of the septal-hippocampal cholinergic neurons. Life Sci. 32: 165-179.

De Belleroche, J. S., and H. F. Bradford (1977) On the site of origin of transmitter amino acid released by depolarization of nerve terminal in vitro. J. Neurochem. 29: 335-343.

De Feudis, F. V. (1984) Review. GABA and endocrine regulation. Relation to neurologic-psychiatric disorders. Neurochem. Int. 6:116.

De France, J. F. (1976) A functional analysis of the septal nuclei. In The Septal Nuclei. Advances in Behavioral Biology, Vol. 20, J. F. De France, ed., pp. 185-227, Plenum, New York.

DeVries, G. J., and R. M. Buijs (1983) The origin of the vasopressinergic and oxytocinergic innervation of the rat brain with special reference to the lateral septum. Brain Res. 273: 307-317.

Dutar, P., Y. Lamour, and A. Jobert (1985) Septohippocampal neurons in the rat: An in vivo intracellular study. Brain Res. 340: 135142.

Gall, C., and R. Y. Moore (1984) Distribution of enkephalin, substance $P$, tyrosine hydroxylase, and 5-hydroxytryptamine immunoreactivity in the septal region of the rat. J. Comp. Neurol. 225: 212-227.

Gamrani, H., B. Onténiente, P. Seguela, M. Geffard, and A. Calas (1986) Gamma-aminobutyric acid-immunoreactivity in the rat hip- 
pocampus. A light and electron microscopic study with anti-GABA antibodies. Brain Res. 364: 30-38.

Jennes, L., W. E. Stumpf, and M. L. Tappaz (1983) Anatomical relationships of dopaminergic and GABAergic systems with the GnRHsystems in the septo-hypothalamic area. Immunohistochemical studies. Exp. Brain Res. 50:91-99.

Kah, O., P. Dubourg, B. Onténiente, M. Geffard, and A. Calas (1986) The dopaminergic innervation of the goldfish pituitary: An immunocytochemical study at the electron microscope level using antibodies against dopamine. Cell Tissue Res. 244: 577-582.

Köhler, C., and V. Chan-Palay (1983) Distribution of gamma aminobutyric acid containing neurons and terminals in the septal area. An immunohistochemical study using antibodies to glutamic acid decarboxylase in the rat brain. Anat. Embryol. 167: 53-66.

Köhler, C., V. Chan-Palay, and H. Steinbusch (1982) The distribution and origin of serotonin-containing fibers in the septal area: A combined immunohistochemical and fluorescent retrograde tracing study. J. Comp. Neurol. 209: 91-111.

Köhler, C., V. Chan-Palay, and J.-Y. Wu (1984) Septal neurons containing glutamic acid decarboxylase immunoreactivity project to the hippocampal region in the rat brain. Anat. Embryol. 169: 41-44.

Kuriyama, K. (1976) Subcellular localization of the GABA system in brain. In GABA in Nervous System Function, R. E. Roberts, T. N. Chase, and D. B. Tower, eds., pp. 187-196, Raven, New York

Lindvall, O., and U. Stenevi (1978) Dopamine and noradrenaline neurons projecting to the septal area in the rat. Cell Tissue Res. 190: 383-407.

McLennan, H., and J. J. Miller (1974) $\gamma$-Aminobutyric acid and inhibition in the septal nuclei of the rat. J. Physiol. (Lond.) 237:625633.

Mangan, J. L., and V. P. Whittaker (1966) The distribution of free amino acids in subcellular fractions of guinea-pig brain. Biochem. J. 98: 128-137.

Maxwell, D. J., C. Leranth, and A. A. J. Verhofstad (1983) Fine structure of serotonin-containing axons in the marginal zone of the rat spinal cord. Brain Res. 266: 253-259.

Moore, R. Y. (1978) Catecholamine innervation of the basal forebrain. I. The septal area. J. Comp. Neurol. 177: 665-684.

Mugnaini, E. (1985) GABA neurons in the superficial layers of the rat dorsal cochlear nucleus: Light and electron microscopic immunocytochemistry. J. Comp. Neurol. 235: 61-81.

Mugnaini, E., and W. H. Oertel (1985) An atlas of the distribution of GABAergic neurons and terminals in the rat CNS as revealed by GAD immunocytochemistry. In Handbook of Chemical Neuroanato$m y$, Vol. 4, A. Björklund and T. Hökfelt, eds., pp. 436-608, Elsevier, Amsterdam, New York, Oxford.

Oertel, W. H., C. Nitsch, and E. Mugnaini (1984) The immunocytochemical demonstration of the GABAergic neurons in rat globus pallidus and nucleus entopeduncularis and their GABAergic innervation. Adv. Neurol. 40: 91-98.

Onténiente, B., M. Geffard, and A. Calas (1984) Ultrastructural immunocytochemical study of the dopaminergic innervation of the rat lateral septum with anti-dopamine antibodies. Neuroscience 13:385393.

Onténiente, B., H. Tago, H. Kimura, and T. Maeda (1986) Distribution of GABA-immunoreactive neurons in the septal region of the rat brain. J. Comp. Neurol. 248: 422-430.

Ottersen, O. P., and J. Storm-Mathisen (1984) Neurons containing or accumulating transmitter amino acids. In Handbook of Chemical Neuroanatomy, Vol. 3, A. Björklund, T. Hökfelt, and M. J. Kuhar, eds., pp. 141-246, Elsevier, Amsterdam, New York, Oxford.

Palkovits, M., and M. J. Brownstein (1985) Distribution of neuropeptides in the central nervous system using biochemical micromethods. In Handbook of Chemical Neuroanatomy, Vol. 4, A. Björklund and T. Hök felt, eds., pp. 1-71, Elsevier, Amsterdam, New York, Oxford.

Panula, P., A. V. Revuelta, D. L. Cheney, J.-Y. Wu, and E. Costa (1984) An immunohistochemical study on the location of GABAergic neurons in the rat septum. J. Comp. Neurol. 222:69-80.

Paxinos, G., and C. Watson (1982) The Rat Brain in Stereotaxic Coordinates. Academic, London.

Pickel, V. M. (1985) General morphological features of peptidergic neurons. In Handbook of Chemical Neuroanatomy, Vol. 4, A. Björklund and T. Hökfelt, eds., pp. 72-92, Elsevier, Amsterdam, New York, Oxford.

Poulain, P., L. Martin-Bouyer, J. C. Beauvillain, and G. Tramu (1984) Study of the efferent connections of the enkephalinergic magnocellular dorsal nucleus in the guinea-pig hypothalamus using lesions, retrograde tracing and immunohistochemistry: Evidence for a projection to the lateral septum. Neuroscience 11: 331-343.

Ribak, C. E., J. E. Vaughn, and R. P. Barber (1981) Immunocytochemical localization of GABAergic neurons at the electron microscopical level. Histochem. J. 13: 55-58.

Ribak, C. E., J. E. Vaughn, and E. Roberts (1979) The GABA neurons and their axon terminals in rat corpus striatum as demonstrated by GAD immunocytochemistry. J. Comp. Neurol. 187: 261-284.

Ribak, C. E., J. E. Vaughn, and K. Saito (1978) Immunocytochemical localization of glutamic acid decarboxylase in neuronal somata following colchicine inhibition of axonal transport. Brain Res. 140:315332.

Seguela, P., M. Geffard, R. M. Buijs, and M. Le Moal (1984) Antibodies against $\gamma$-aminobutyric acid: Specificity studies and immunocytochemical results. Proc. Natl. Acad. Sci. USA 81: 3888-3892.

Seguela, P., H. Gamrani, M. Geffard, A. Calas, and M. Le Moal (1985) Ultrastructural immunocytochemistry of $\gamma$-aminobutyrate in the cerebral and cerebellar cortex of the rat. Neuroscience 16: 865-874.

Simon, H., M. Le Moal, D. Galey, and B. Cardo (1979) Selective degeneration of central dopaminergic systems after injection of 6-hydroxydopamine in the ventral mesencephalic tegmentum of the rat: Demonstration by the Fink-Heimer stain. Exp. Brain Res. 20: 375-384.

Somogyi, P., A. Hodgson, I. W. Chubb, B. Penke, and A. Erdei (1985) Antisera to $\gamma$-aminobutyric acid. II. Immunocytochemical application to the central nervous system. J. Histochem. Cytochem. 33:240248.

Swanson, L. W., and W. M. Cowan (1979) The connections of the septal region in the rat. I. Comp. Neurol. 186: 621-656.

Swanson, L. W., and B. K. Hartman (1975) The central adrenergic system. An immunofluorescence study of the location of cell bodies and their efferent connections in the rat utilizing dopamine- $\beta$-hydroxylase as a marker. J. Comp. Neurol. 186: 467-506.

Walaas, I., and F. Fonnum (1979) The distribution of monoamines GABA, acetylcholine and glutamate fibers in the mesolimbic system. In GABA Neurotransmitters. Pharmacological, Biochemical and Physiological Aspects, P. Krogsgaard-Larsen, J. Scheel-Krüger, and H. Kofod, eds., pp. 60-73, Plenum, New York. 